\title{
Evidence for the Direct Desorption of Crown Ether-Metal Ion Complexes in Liquid Secondary Ionization Mass Spectrometry
}

\author{
John B. Cunniff and Paul Vouros \\ Department of Chemistry and Barnett Institute, Northeastern University, Boston, Massachusetts, USA
}

Dave L. Kaplan and Steve A. Fossey

Bintechnolngy Branch, U.S. Army Natick Research, Development and Engineering Center, Natick, Massachusetts, USA

The liquid secondary ionization mass spectra of crown ether solutions and crown ether solutions containing alkali metal cations were generated. Cesium cations acted as both the primary ion beam and as a competing gas-selvedge-phase reactant. The data suggest that crown ether complexes formed in the condensed phase survive intact the fast ion bombarding event and the transition into the gas phase. The data further suggest that crown ether complexes formed in the condensed phase predominate in the ion spectrum over the corresponding complexes formed in the selvedge. (J Am Soc Mass Spectrom 1994, 5, 638-648)

$\mathrm{I}$ n the past decade, fast-atom bombardment mass spectrometry (FAB-MS) and liquid secondary ionization mass spectrometry (LSIMS) have become important techniques that permit the analysis of polar and nunvolatile substances [1-4]. A prominent feature of FAB and LSIMS is cluster ion formation. For example, when glycerol is used as a matrix, protonated clusters are routinely observed where hydrogen bonding is the likely force holding these clusters together. Analyte clusters also have been detected by FAB-MS. In their use of FAB-MS for the sequence determination of peptides, Roepstorff et al. [5] observed dimerization of selected acetylated and underivatized tripeptides. Meijers et al. [6] showed that cluster formation is a common phenomenon of the FAB mass spectra of porphyrins and suggested that such cluster formation may be important in the tumor localization process. Hydrogen bonding has been invoked to explain the occurrence of dimers between pyridinium ions and other electron donors [7]. Ions that reflect intermolecular associations also have been reported by Williams et al. [3] in two examples of the FAB spectra of binary peptide mixtures. Some selectivity was apparent, but the authors caution against the quantitative interpretation of the FAB data generated from the condensedphase interaction of two ligands that differ widely in mass.

For FAB (or LSIMS), the contribution of gasselvedge ionization processes (selvedge is a high density hot gas located at or near the surface) versus the

Address reprint requests to Dr. Paul Vouros, Chemistry Department, 101 Hurtig Hall, Northeastern University, Boston, MA 02115. direct desorption of preformed ions has been the subject of considerable debate [8-10]. It is interesting to note that this debate is still unresolved 10 years after the introduction of FAB. Perhaps, the reason that more resources have not been invested to resolve this debate lies in a simple truth: the technique works, and therefore the ion formation mechanism is of secondary interest to those who utilize the technique primarily as a means of introducing nonvolatile compounds into the gas phase for mass spectral analyses. There is, however, a particular area of research where this issue must be resolved before any meaningful mass spectral data may be generated. This area involves the analysis of noncovalent complexes. Because the nature and degree of aggregation is likely to be solution-dependent, it is imperative to ascertain whether the origin of non-covalently bound species stems from the condensed phase or from the gas phase. This issue is particularly important when probing host-guest interactions. If gas-phase processes create the detected complex, then the spectrum is the result of an experimental artifact. If this is the case, the FAB technique in mass spectrometry will be limited to a minor role in the important task of probing condensed phase molecular complexes. Recently, Henion and co-workers $[11,12]$ reported the first successful application for the detection of noncovalent receptor-ligand complexes by using continuous-introduction ion spray mass spectrometry. This report has generated considerable interest because of the potential to probe host- ${ }^{-}$uest interactions. Although there has been experimental evidence that suggests that the FAB mass spectrum also adequately represents the established equilibrium in the liquid 
state [13], a series of experiments performed by Sunner et al. [14-16], as well as Budzikiewicz and co-workers [17], have strongly argued that ionization is primarily a gas-selvedge-phase phenomenon.

To help elucidate whether a selvedge-phase versus a condensed-phase phenomenon was responsible for the formation of noncovalent complexes, our group [18] originally proposed the use of a split probe (a probe tip that was divided horizontally by a paraffin barrier). Subsequent FAB split-probe-tip experiments by Balasanmugam and co-workers $[19,20]$ demonstrated that gas-phase ligand reactions and substitutions may occur, but that their quantitative contribution to the total ion signal could not be assessed. Although an effort was made to eliminate the possibility for cross-contamination between the split tip for both experiments, the possibility of adsorption of a volatile ligand from one side of the split probe onto the adjacent liquid matrix, followed by sputtering back into the vacuum, could not be ruled out. A later divided probe experiment conducted by our group [21] described significant differences in the relative ion abundances of crown ether-metal complexes when comparing data from a split probe (alkali metal on one half and crown ether on the other half) with singleprobe (alkali metals are mixed with crown ether on a single probe) experiments. Adsorption of the crown ether solution, followed by sputtering of the mixed complexes would essentially be a mixed solution phenomenon. Dissimilarities in relative ion abundances found in our earlier study indicate that although adsorption followed by sputtering may occur, some gasphase complexation may be occurring, which would account for the differences in the relative abundances of the mixed complexes.

In the three split-probe studies mentioned [19-21], the noncovalent complex ion abundance that originates from gas-phase interactions (split probe) were always considerably lower than those intensities that arise from mixed solutions on a single probe. The quantitative extent of gas-phase reactions could not be determined. It is probable, however, that even if gas-phase reactions were responsible for the noncovalent species, mixed solutions produce much higher selvedge concentrations of reacting ligands than split-probe experiments would generate. The ion signal contribution from the alkali metal cation in all split-probe experiments (including our own) had been ignored. Finally, the gas-phase model would predict that the signal from the ion complex would be a function of the gas-phase concentration of the crown ether as well as that of the alkali metal cation. Merely stating that equimolar concentration solutions of alkali metals were placed on one half of a split probe does not necessarily ensure that equal concentrations of the cations are sputtered into the gas phase. Thus a premise of the split-probe experiments of generating the same gasphase concentrations as that generated by single probe experiments was never determined and is probably incorrect. This alone can account for the different characteristics of the spectra. Thus, the informational utility of the split-probe experiment is limited at best.

Prior experiments by Johnstone et al. [22] presented evidence that supported the claim that, for alkali metal-crown ethers, the complex ion signal from FAB is a result of direct desorption from the condensed phase. Contradictory data, however, involving 15crown-5 were not addressed. Further evidence that supported the direct desorption of alkali metal-crown ether complexes was supplied when Bonas et al. [23] accurately determined stability constants in glycerol for 18-crown-6-alkali metal mixtures via FAB-MS. As mentioned previously, however, other similar experiments that determined the $p$ Kas of acids [13] and that stated that gas-phase ions accurately reflected solution-phase conditions were effectively refuted by subsequent experiments that favored the gas-selvedge model [14-17]. Thus, it is currently unclear whether the observed complexes are preformed in condensed media and then desorbed or are formed in the gas phase after desorption [24].

Ideally, the extent of gas-phase reaction contribution to the ligand-ligand ion signal could be quantitated by performing a split-probe experiment whereby the differing ligands were separated on the order of angstroms and in which cross-contamination between differing solutions could be ruled out. However, the construction of such a probe tip is not possible. Therefore, another experiment is needed that introduces a high concentration of ligand $A$, for example, into the selvedge of ligand $\mathrm{B}$, while maintaining zero or close to zero concentration of ligand $A$ in the solution of ligand B. In this manner, the extent of gas-phase contribution to the signal from the complex may be assessed.

To that effect, the recent results of Zhang et al. [24, 25], who demonstrated that alkali cations can react unambiguously with crown ethers in the gas phase, and those of Katritzky et al. [26], who determined the gas-phase binding energies of several crown ethers with metal ions via Fourier-transform ion syclotron resonance mass spectrometry, may help to quantify the contribution of the gas-phase-generated interactions. Their results are employed in the present study to propose that the observed complex ion abundances are contrary to gas-phase model processes and instead indicative of condensed-phase complexation.

$\mathrm{Up}$ to this point, we have referred to gas-phase and selvedge-phase processes as synonymous. In fact there is a significant difference between the two processes that we shall now outline. As mentioned previously, the selvedge is the high density hot gas located at or near the surface whereas the gas phase is that phase beyond the selvedge and extending throughout the source. More importantly, ions desorbed from the liquid matrix will rapidly achieve relatively high energies within the gas phase as a result of the pull of the extraction voltage. The selvedge ions will have low energies as a result of this pull because of the very 
small distance within the selvedge where the extraction voltage can exert its force. For this reason, gasphase complexation per se should be insignificant compared to that within the selvedge because the reactants would be too energetic to form complexes. Thus we shall henceforth refer to all nonsolution complexation in our current study as selvedge-phase complexation rather than gas-phase complexation, even though previous studies have referred to them as gasphase reactions.

1<smiles>C1COCCOCCOCCOC1</smiles>

12-crown-4<smiles>C1COCCOCCOCCOCCO1</smiles>

15-crown-5<smiles>CCOCCOCCOCCOCCOC[AsH2]</smiles>

Along these lines, we discuss here the liquid secondary ionization (LSI) mass spectra of three crown ethers $\left(\begin{array}{ll}1 & 3\end{array}\right)_{r}$, as well as equimolar crown cther-alkali metal solutions. We have chosen to study this system because there exists a vast amount of information on the formation constants of crown ether metal ion complexes. The study of these compounds dates back to the original discovery by $C$. J. Pedersen that crown ethers have the urique ability to form stable complexes with metal and primary alkyl ammonium cations which in turn opened up new horizons in organic chemistry [27]. Since then, crown ether-metal ion complexes have been studied and reported extensively $[28,29]$. The most frequently used crown ethers are the three empluyed in uur study [27]. In our present study, we have used as the primary ion beam cesium cations, which is also a well studied ligand with these crown ethers. Thus, the cesium ion is nol only responsible for the fast-ion bombarding event, but is also present at a high concentration in the selvedge whereas it is not present in the solution. The results

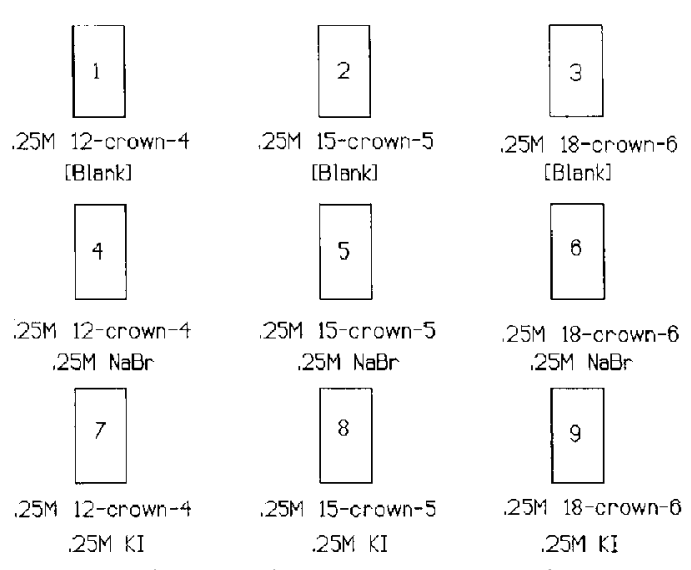

Figure 1. Solutions and concentrations prepared in $1: 1 \mathrm{v} / \mathrm{v}$ glycerol-water matrix.

presented here are consistent with the occurrence of a selvedge-derived ionization for crown ether-alkali metal complexes. However, the quantitative contribution to the ion signal is very small compared to the signal generated by direct desorption when preformed species are present in the condensed phase.

\section{Experimental}

Nine solutions were prepared in a $1: 1 \mathrm{v} / \mathrm{v}$ glycerolwater matrix. Figure 1 illustrates the composition of these solutions. Approximately $5 \mu \mathrm{L}$ of each solution were deposited onto a stainless-steel FAB probe tip and inserted into the FAB source.

LSI mass spectra were obtained on a Fisons VG Quattro triple-quadrupole mass spectrometer. Cesium cations were used as the bombarding beam with ion gun energies of $8 \mathrm{keV}$ and a gun current of approximately $0.1 \mu \mathrm{A}$. Spectra were acquired at a rate of $1 \mathrm{~s}$ over a range of $800 \mathrm{u}$ and over a period of several minutes for each solution. A minimum of three separate analyses were performed for each of the 9 solutions (27 total analyses) and the repeat analyses were very reproducible. The source volume was cleared between all analyses. The source was operated at ambient temperature and the analyzer was operated at nominal resolving power.

\section{Results and Discussion}

Solution Concentrations of Crown Ethers
$K_{(a q)}^{+}, \mathrm{Na}_{(a q)}^{+}$, and Complexes
$(a q)$

Before the spectra may be evaluated, it is important to establish the solution concentrations of the crown ether-metal ion complexes. The stability of crown ether-metal ion complexes is often rationalized by the concept of complementarity. Thus, greater stability arises from a better electronic match and/or steric 
compatibility. The converse is also true. Exact stability constants from different solvents vary somewhat depending on the source of the data, although the general trends of stability appear to be fairly consistent. Table 1 lists the log of the stability constants of potassium, sodium, and cesium cations complexed with 18 -crown-6, 15 -crown- 5 , and 12 -crown- 4 in a variety of solvents.

Although there is a fair amount of spread in the data, the order of the alkali metal-crown ether complex stabilities in all the matrices containing 18-crown-6 follows the trend $\mathrm{K}^{+}>\mathrm{Cs}^{+}>\mathrm{Na}^{+}$. For 15 -crown-5, the order is more ambiguous and appears to be virtually equal for all three complexes. Finally, from the limited data on 12-crown-4 and considering steric constraints, the order of stabilities in a glycerol-water solution should follow $\mathrm{Na}^{+}>\mathrm{K}^{+}>\mathrm{Cs}^{+}$, with the possibility that a complex with cesium does not form.

The availability of stability constants Ks for alkali metal complexes with 18-crown-6 in a variety of matrices, including glycerol and water, makes it possible to approximate the complex concentrations for the three solutions that contain 18-crown-6 (solutions 3, 6, and 9 from Figure 1) in a 1:1 glycerol-water matrix.

As Bonas et al. [23] previously noted, there exists a degree of linearity between the dielectric constant of a matrix and the $\log K s$ of the ligand-metal ion complexes dissolved in the matrix. In Figure 2, the $\log K s$

Table 1. $\Delta G^{0}$ and $\log K s$ values for crown ether-metal ion complexes in common matrix ${ }^{\mathrm{a}}$

\begin{tabular}{|c|c|c|c|c|}
\hline Crown ether & Solvent at $25^{\circ} \mathrm{C}$ & Cation & $\Delta \mathrm{G}^{\mathrm{Ob}}$ & $\log K s^{c}$ \\
\hline $\begin{array}{l}\text { 18-Crown-6 } \\
18-\text { Crown-6 } \\
18-\text { Crown-6 }\end{array}$ & $\begin{array}{l}\mathrm{H}_{2} \mathrm{O} \\
\mathrm{H}_{2} \mathrm{O} \\
\mathrm{H}_{2} \mathrm{O}\end{array}$ & $\begin{array}{l}\mathrm{Na}^{+} \\
\mathrm{K}^{+} \\
\mathrm{Cs}^{+}\end{array}$ & $\begin{array}{l}1.1 \\
2.65-3.1 \\
1.35\end{array}$ & $\begin{array}{l}- \\
- \\
-\end{array}$ \\
\hline $\begin{array}{l}\text { 18-Crown-6 } \\
18-\text { Crown-6 } \\
18-\text { Crown-6 }\end{array}$ & $\begin{array}{l}\mathrm{MeOH} \\
\mathrm{MeOH} \\
\mathrm{MeOH}\end{array}$ & $\begin{array}{l}\mathrm{Na}^{+} \\
\mathrm{K}^{+} \\
\mathrm{Cs}^{+}\end{array}$ & $\begin{array}{l}5.89-5.92 \\
8.27-8.40 \\
6.54-6.06\end{array}$ & 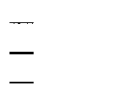 \\
\hline $\begin{array}{l}\text { 18-Crown-6 } \\
18 \text { Crown-6 } \\
18-\text { Crown-6 }\end{array}$ & $\begin{array}{l}\mathrm{MeOH} / \mathrm{H}_{2} \mathrm{O}(7 / 3) \\
\mathrm{MeOH} / \mathrm{H}_{2} \mathrm{O}(7 / 3) \\
\mathrm{MeOH} / \mathrm{H}_{2} \mathrm{O}(7 / 3)\end{array}$ & $\begin{array}{l}\mathrm{Na}^{+} \\
\mathrm{K}^{+} \\
\mathrm{Cs}^{+}\end{array}$ & $\begin{array}{l}3.76 \\
5.90 \\
3.87\end{array}$ & $\begin{array}{l}- \\
- \\
-\end{array}$ \\
\hline $\begin{array}{l}\text { 18-Crown-6 } \\
18-\text { - rown-6 } \\
18-\text { Crown-6 }\end{array}$ & $\begin{array}{l}\mathrm{H}_{2} \mathrm{O} \\
\mathrm{H}_{2} \mathrm{O} \\
\mathrm{H}_{2} \mathrm{O}\end{array}$ & $\begin{array}{l}\mathrm{Na}^{+} \\
\mathrm{K}^{+} \\
\mathrm{Cs}^{+}\end{array}$ & $\begin{array}{l}- \\
-\end{array}$ & $\begin{array}{l}0.3-1.8 \\
2.03-2.15 \\
0.80-0.99\end{array}$ \\
\hline $\begin{array}{l}\text { 18-Crown-6 } \\
18-\text { Crown-6 } \\
18-\text { Crown-6 }\end{array}$ & $\begin{array}{l}\mathrm{MeOH} \\
\mathrm{MeOH} \\
\mathrm{MeOH}\end{array}$ & $\begin{array}{l}\mathrm{Na}^{+} \\
\mathrm{K}^{+} \\
\mathrm{Cs}^{+}\end{array}$ & $\frac{-}{-}$ & $\begin{array}{l}4.32-4.46 \\
5.93-6.20 \\
4.49-4.79\end{array}$ \\
\hline $\begin{array}{l}\text { 18-Crown-6 } \\
18-\text { Crown-6 } \\
18-\text { Crown-6 }\end{array}$ & $\begin{array}{l}\mathrm{MeOH} / \mathrm{H}_{2} \mathrm{O}(7 / 3) \\
\mathrm{MeOH} / \mathrm{H}_{2} \mathrm{O}(7 / 3) \\
\mathrm{MeOH} / \mathrm{H}_{2} \mathrm{O}(7 / 3)\end{array}$ & $\begin{array}{l}\mathrm{Na}^{+} \\
\mathrm{K}^{+} \\
\mathrm{Cs}^{+}\end{array}$ & $\begin{array}{l}- \\
-\end{array}$ & $\begin{array}{l}2.76 \\
4.33 \\
2.84\end{array}$ \\
\hline $\begin{array}{l}\text { 18-Crown-6 } \\
18 \text {-Crown-6 } \\
18 \text {-Crown-6 }\end{array}$ & $\begin{array}{l}\text { Glycerol } \\
\text { Glycerol } \\
\text { Glycerol }\end{array}$ & $\begin{array}{l}\mathrm{Na}^{+} \\
\mathrm{K}^{+} \\
\mathrm{Cs}^{+}\end{array}$ & - & $\begin{array}{l}4.32-4.46 \\
5.93-6.20 \\
4.49-4.79\end{array}$ \\
\hline $\begin{array}{l}\text { 18-Crown-6 } \\
\text { 18-Crown-6 } \\
18 \text {-Crown-6 } \\
18 \text {-Crown-6 }\end{array}$ & $\begin{array}{l}\text { MeCN } \\
\text { MeCN } \\
\text { MeCN } \\
\text { MeCN }\end{array}$ & $\begin{array}{l}\mathrm{Na}^{+} \\
\mathbf{K}^{+} \\
\mathrm{Cs}^{+} \\
\mathbf{H}^{+}\end{array}$ & $\begin{array}{l}6 / 43-6 / 5 \\
7.8 \\
6.92 \\
8.9\end{array}$ & - \\
\hline $\begin{array}{l}15-\text { Crown-5 } \\
15 \text {-Crown-5 } \\
15 \text {-Crown-5 }\end{array}$ & $\begin{array}{l}\mathrm{H}_{2} \mathrm{O} \\
\mathrm{H}_{2} \mathrm{O} \\
\mathrm{H}_{2} \mathrm{O}\end{array}$ & $\begin{array}{l}\mathrm{Na}^{+} \\
\mathrm{K}^{+} \\
\mathrm{Cs}^{+}\end{array}$ & $\begin{array}{l}0.95 \\
1.01 \\
1.1\end{array}$ & - \\
\hline $\begin{array}{l}15 \text {-Crown-5 } \\
15 \text {-Crown-5 } \\
15 \text {-Crown-5 }\end{array}$ & $\begin{array}{l}\mathrm{MeOH} \\
\mathrm{MeOH} \\
\mathrm{MeOH}\end{array}$ & $\begin{array}{l}\mathrm{Na}^{+} \\
\mathrm{K}^{+} \\
\mathrm{Cs}^{+}\end{array}$ & $\begin{array}{l}4.1-4.5 \\
3.41-5.26 \\
2.97-4.88\end{array}$ & - \\
\hline $\begin{array}{l}15-\text { Crown-5 } \\
15 \text {-Crown-5 } \\
15 \text {-Crown-5 }\end{array}$ & $\begin{array}{l}\text { MeCN } \\
\text { MeCN } \\
\text { MeCN }\end{array}$ & $\begin{array}{l}\mathrm{Na}^{+} \\
\mathrm{K}^{+} \\
\mathrm{Cs}^{+}\end{array}$ & $\begin{array}{l}6.70-6.79 \\
5.83-5.91 \\
4.24\end{array}$ & $\begin{array}{l}- \\
-\end{array}$ \\
\hline $\begin{array}{l}12-\text {-Crown-4 } \\
12 \text {-Crown-4 }\end{array}$ & $\begin{array}{l}\mathrm{MeOH} \\
\mathrm{MeOH}\end{array}$ & $\begin{array}{l}\mathbf{K}^{+} \\
\mathrm{Na}^{+}\end{array}$ & $\begin{array}{l}2.11-2.16 \\
2.39\end{array}$ & - \\
\hline $\begin{array}{l}\text { 12-Crown-4 } \\
12 \text {-Crown-4 } \\
12 \text {-Crown-4 }\end{array}$ & $\begin{array}{l}\mathrm{MeCN} \\
\mathrm{MeCN} \\
\mathrm{MeCN}\end{array}$ & $\begin{array}{l}\mathbf{K}^{+} \\
\mathrm{Li}^{+} \\
\mathbf{H}^{+}\end{array}$ & $\begin{array}{l}3.27 \\
5.80 \\
3.47\end{array}$ & $\frac{-}{-}$ \\
\hline
\end{tabular}

\footnotetext{
a Vogtle, F.; Weber, E. In Crown Ethers and Analogs; John Wiley \& Sons Ltd.: Chichester, $1989 ;$ Ch. 4.

Inoue, Y.; Hakushi, T. In Cation Binding by Macrocycles, Complexation of Cationic Species by Crown Ethers; Marcel Dekker; New York, 1990; Chap. 1.

${ }^{\mathrm{B}}$ Bonas, G.; Bosso. C.; Vignon, M. R. Rapid Commun. Mass Spectrom. 1988, 2, 88-89.
} 
for selected alkali metals complexes with 18 -crown-6 is plotted against the dielectric constant of a variety of solvents. Based on a simple addition relationship for dielectric constants and for log $K s$, a value for $K s$ for the potassium cation complex and the sodium cation complex with 18-crown-6 in a $1: 1 \mathrm{v} / \mathrm{v}$ water-glycerol solvent may be approximated [23].

From Figure 2, the calculated log $K s$ are

\begin{tabular}{ccr} 
Complex & $\log K s$ & \multicolumn{1}{c}{$K s$} \\
\hline \hline 1 8-crown-6-K ${ }^{+}$complex & 3.4 & 2510 \\
1 8-crown-6- $\mathrm{Na}^{+}$complex & 1.7 & 50
\end{tabular}

From the stability constant and the quadratic equation, the concentration of the ion complex in solution then may be calculated:

$$
\mathrm{M}^{+}+\mathrm{CE} \Leftrightarrow \text { complex }
$$

According to the equilibrium expression,

$$
K=\frac{[\text { complex }]}{\left.\{[\text { CE }]-[\text { complex }]\}\left[\mathrm{M}^{+}\right]-[\text {complex }]\right\}}
$$

where [Complex] is the concentration of complex, [CE] is the formal concentration of crown ether (complexed plus uncomplexed), and $\left[\mathrm{M}^{+}\right]$is the formal concentra- tion of metal cation (complexed plus uncomplexed). The solution concentration of the complex may be obtained from eq 1 as

[complex]

$=\frac{K[C E]+K\left[M^{+}\right]+1-\left\{\left(K[C E]+K\left[M^{+}\right]+1\right)^{2}-4 K^{2}[C E]\left[M^{+}\right]\right\}^{1 / 2}}{2 K}$

Thus the concentration of the complex, alkali metal cation, and uncomplexed 18-crown-6 may be calculated for the three equimolar $(0.25 \mathrm{M})$ solutions that

\begin{tabular}{|c|c|c|c|c|}
\hline Solution & [CE] & {$\left[K^{+}\right]$} & {$\left[\mathrm{Na}^{+}\right]$} & {$\left[\mathrm{CE}-\mathrm{M}^{\dagger}\right]$} \\
\hline $3_{(18-\text { crown-6) }}$ & 0.25 & 0.0 & 0.0 & $\overline{0.00}$ \\
\hline $6_{(18-\text { grown-6-Nat) }}$ & 0.06 & - & 0.06 & 0.19 \\
\hline $9_{(18 \text {-crown-6-k+1 }}$ & 0.01 & 0.01 & - & 0.24 \\
\hline
\end{tabular}
contain 18-crown-6:

where $[\mathrm{CE}]$ is the molar concentration of uncomplexed 18-crown-6, [ $\left.\mathrm{K}^{+}\right]$is the molar concentration of potassium cation, $\left[\mathrm{Na}^{+}\right]$is the molar concentration of sodium cation, $\left[\mathrm{CE}-\mathrm{M}^{+}\right.$] is the molar concentation of complexed 18-crown-6. Accordingly, $96 \%$ of the potas-

\begin{tabular}{|c|c|c|c|c|c|c|c|c|c|c|}
\hline & $\mathrm{H} 2 \mathrm{O}$ & $\mathrm{MeOH}$ & $\underline{70 \% \mathrm{MeOH}}$ & GLYCEROL & & $\mathrm{H} 2 \mathrm{O}$ & $\mathrm{MeOH}$ & $\underline{70 \%} \mathrm{MeOH}$ & GLYCEROL & 80/60 H/2O/glyc. \\
\hline $\mathrm{F}$. & 78.54 & 32.63 & 46.4 & 42.5 & $\mathbf{E}$ & 78.54 & 32.63 & 46.4 & 42.5 & 60.6 \\
\hline $\mathrm{Na}^{+}$ & $0.3-1.8$ & $4.32-4.46$ & 2.76 & 2.32 & $\mathrm{Na}^{+}$ & 1.1 & 4.39 & 2.75 & 2.32 & $1.7 !$ \\
\hline $\mathbf{K}^{+}$ & $2.03-2.15$ & $5.93-6.20$ & 4.33 & 4.65 & $\mathbf{K}^{+}$ & 2.09 & 6.06 & 4.33 & 4.65 & 3.37 \\
\hline $\mathbf{R b}^{+}$ & 1.86 & $6.32-6.73$ & 3.46 & 3.79 & $\mathbf{R} \mathbf{b}^{+}$ & 1.56 & 5.53 & 3.46 & $3.7 \theta$ & 2.68 \\
\hline $\mathrm{Gs}^{+}$ & $.9-.99$ & $\begin{array}{c}4.49 \times 4.79 \\
\mathbf{a}\end{array}$ & 2.84 & 2.63 & $\mathrm{Cs}^{+}$ & .895 & 4.64 & $b^{2.84}$ & 2.63 & 1.76 \\
\hline
\end{tabular}
sium cation is complexed with crown ether in solution

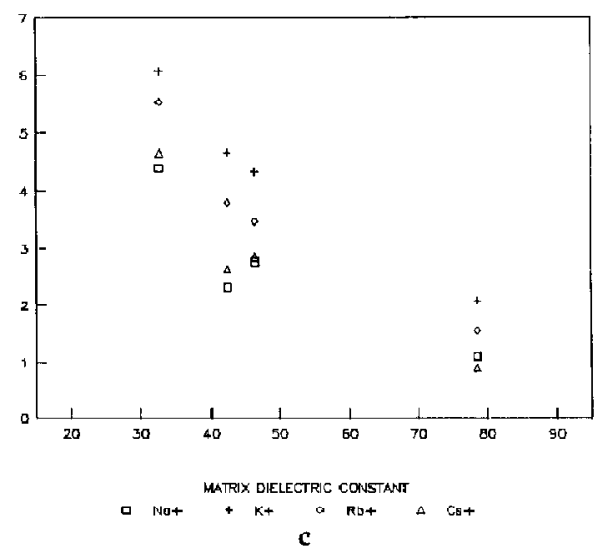

Figure 2. (a) Diclectric constants and $\log$ of stability constants of 18 -crown-6/metal cation complexes (from Bonas, G.; Bosso, C.; Vignon, M. R. Rapid Commun. Mass Spectrom. 1988, 2, 88-89). (b) Median values from (a) and interpolated values for log stability constants for 18-crown-6- $\mathrm{K}^{+}$and 18-crown-6-Na ${ }^{+}$in various matrices. (c) Graph of matrix dielectric constant versus median value of $\log K s$ of 18 -crown- 6 -alkali metal cation complexes. 
9 and $76 \%$ of the sodium cation is complexed with crown ether in solution 6 .

It should be noted here that these are the calculated concentrations of complex within the 50:50 glycerolwater matrix at standard temperature and pressure. These conditions are not present in the FAB ion source. The impacting primary ion beam may heat up the solution somewhat and tend to cause an increase in dissociation of the complex. This heating effect should, however, be very small. The low pressure of the source will result in a preferential evaporation of the water component of the surface of the matrix, leaving behind the lower dielectric glycerol matrix. The lower dielectric constant of the glycerol should result in an increase of complex concentration. The two factors act in opposing manners and it may still be concluded that, within the solution, a majority of the alkali metal cations remain complexed with crown ethers, in accordance with the stability constants, during the $\mathrm{FAB}$ experiment.

Selvedge-Phase Concentrations of Crown Ethers $(g)$ ' $\mathrm{Na}_{(g)}^{+}, \mathrm{K}_{(g)}^{+}, \mathrm{Cs}_{(g)}^{+}$, and Complexes $(g)$

Due to the rapid formation and extinction of the selvedge, we can assume that the selvedge density is nearly equivalent to the solution density. Therefore, the solution and selvedge concentrations also should be nearly equivalent. It is helpful, however, to obtain a clearer picture of the event that takes place during the $\mathrm{FAB}$ process by calculating the following two quantities:

1. Concentration of the alkali metal cations and crown ether in solution in units of molecules per cubic angstrom $\left(\AA^{3}\right)$. The concentration of alkali cation and crown ether (complexed plus uncomplexed) per cubic angstrom of solution is $1.5 \times 10^{-4}$ molecules $/ \AA^{3}$ or 1 molecule per $6600 \AA^{3}$ which is equivalent to having one molecule in a cube with dimensions approximating $19 \times 19 \times 19 \AA$ :

2. The area and rate of impact of $\mathrm{Cs}^{+}$cations. Before an accurate calculation could be made for the area and rate of impact by $\mathrm{Cs}^{+}$cations, the total surface area of impact by the primary ion beam had to be determined. This was done by affixing a piece of white paper to the tip of the stainless-steel probe and exposing it to the fast-ion beam for approximately $1 \mathrm{~min}$. A circular burn with a radius of 0.5 $\mathrm{mm}$ was observed on the surface and taken as the radius of the area of impact by the primary $\mathrm{Cs}^{+}$ion beam. The instrument was operated at a primary ion beam current of $0.1 \mu \mathrm{A}$.

From the data, it is possible to calculate the impact rate in terms of current in ions per second, which corresponds to

$$
\begin{aligned}
0.1 \times & 10^{-6} \mathrm{C} / \mathrm{s} \times 1 \mathrm{Cs}^{+} \text {ions } / 16022 \times 10^{-19} \mathrm{C} \\
& =6 \times 10^{11} \mathrm{Cs}^{+} \text {cations } / \mathrm{s}
\end{aligned}
$$

The area of impact expressed in square angstroms is

$$
\text { area of impact }=\pi R^{2}=0.8 \mathrm{~mm}^{2}=8 \times 10^{13} \AA
$$

This corresponds to one $\mathrm{Cs}^{+}$ion impact per $130 \AA^{2}$ per second. Because of the relatively large area and long time interval between impacts, each impact may be considered as an isolated event [30]. Assuming a $50 \%$ implantation efficiency, one $\mathrm{Cs}^{+}$cation may reside on the surface of the droplet per $260 \AA^{2}(16 \times 16 \AA)$. This surface concentration is comparable to the previously calculated dimensions for the solution-phase complexes, and it is thus reasonable to expect comparable selvedge concentrations of $\mathrm{Cs}_{(\mathrm{g})}^{+}$and condensedphase-originated alkali cations and crown ethers.

We may now begin to draw a clearer picture of what may be happening during this ion bombardment event. Until now, we have implied that the mechanism for desorption and ionization for FAB and LSIMS are identical, and it is generally recognized that FAB and secondary ionization mass spectrometry (SIMS) reprcsent the same sputtering phenomenon [30]. Markey and Shih [31] also claim that this has been substantiated from data regarding cesium gun equivalence with fast-atom sources. Although we also agree that the sputtering phenomenon is identical for both techniques, it is our belief that the cesium cation becomes involved in selvedge ion chemistry (vide infra).

\section{Solution Concentrations of $\mathrm{Cs}_{(a q)}^{+}$}

The fact that cesium cations are not contained in the condensed phase at any appreciable concentration may be proven from the following calculations. The total number of cesium ions striking the FAB solution per second has been calculated (see above) to be $6 \times 10^{11}$. By comparison, the total number of alkali cations contained in the $5-\mu \mathrm{L}$ droplet of $0.25 \mathrm{M}$ concentration is

$$
=8 \times 10^{20} \text { alkali cations }
$$

If every cesium cation emitted in the primary ion beam were to become soluble in the solution and diffuse rapidly throughout, it would take approximately $10^{9} \mathrm{~s}$ (42 years!) before a concentration of cesium cations comparable to that of the dissolved alkali cations could be obtained. Because of the relative isolation of each event and the slow diffusion that occurs in the viscous glycerol-enriched surface, cesium cations become im- 
pacted into the surface and do not have adequate time to diffuse through the solution or react with another crown ether before they are sputtered out into the selvedge.

Based on these calculations and observations of the generated spectra, we may now proceed to demonstrate that, although not appreciably present in the solution, cesium cations from the ionizing beam are present in the selvedge at concentrations comparable to those of the alkali cations and that they are capable of reacting with crown ethers present in the selvedge phase. The evidence for this is based on five points.

\section{Evidence of Participation of $\mathrm{Cs}^{+}$in Selvedge Reactions}

1. The concentration of alkali metal in solution (or high density selvedge) was found to be one alkali metal molecule (complexed or not complexed) per $6600 \AA^{3}$. These dimensions are comparable to the surface concentration of $\mathrm{Cs}^{+}$evident from the impaction of the primary ion beam and should provide for the theoretical possibility of significant selvedge-phase interactions.

2. Secondary ion yields of between 0.01 and $1 \%$ are common for SIMS [30]. Secondary ion yields are defined as the total number of secondary ions sputtered from the specimen per incident ion of given mass, energy, charge, and angle of incidence [32]. This indicates that there should be between 100 and 10,000 times more cesium cations striking the surface of our droplet than there are total ions ejected from the solution.

3. As noted previously [30], the bulk ( $>99 \%$ ) of the primary $\mathrm{Cs}^{+}$ions impinging on the target are not retrieved as secondary ions. A small fraction of the remaining ions, however, are clearly involved in secondary ion reactions. Ion abundances for $\mathrm{Cs}^{+}$, as measured at the detector of the mass spectrometer and displayed in the spectrum, constitute significant fractions of the spectral peaks for every solution analyzed. Although some of the $\mathrm{Cs}^{+}$ions may have been deflected off the surface without entering the selvedge, these ions must be of sufficiently low energy (and thus capable of complexation) to be trapped and focused by the ion optics of the quadrupole mass analyzer.

4. $\mathrm{A} \mathrm{Cs}_{2} \mathrm{I}^{+}$ion is detected in the spectrum generated from solution 9 (vide infra). This indicates that one cesium cation reacted with an iudide ion to form CsI $_{(g)}$, which, in turn, reacted with a second cesium cation in the gas phase. Also, the complex (18crown-6) ${ }_{2} \mathrm{Cs}^{+}$was detected in the 18-crown-6-blank (solution 3). Again, this indicates at least two collisions involving the gaseous $\mathrm{Cs}^{+}$cation.

5. $\mathrm{Cs}^{+}$-crown ether peaks are observed in the analysis of all three blank solutions that contain only crown ethers.
Thus, selvedge volume-concentration calculations, secondary ion yield calculations, $\mathrm{Cs}^{+}$ion spectra, $\mathrm{Cs}^{+}$ cluster spectra, and $\mathrm{Cs}^{+}$complex spectra all indicate that gaseous $\mathrm{Cs}^{+}$cations are reactive in the LSIMS experiment and that the reactivity leads to a significant contribution to the mass spectra.

\section{Evidence of Direct Desorption of Crown Ether Complexes}

Nine representative spectra of each of the solutions 1-9 are shown in Figures 3-5. Analysis of the spectra of Figures 3-5 yields the following evidence to support the thesis that the crown ether-alkali cation complexes survive the selvedge conditions as opposed to being formed (or reformed after an initial breakup) in
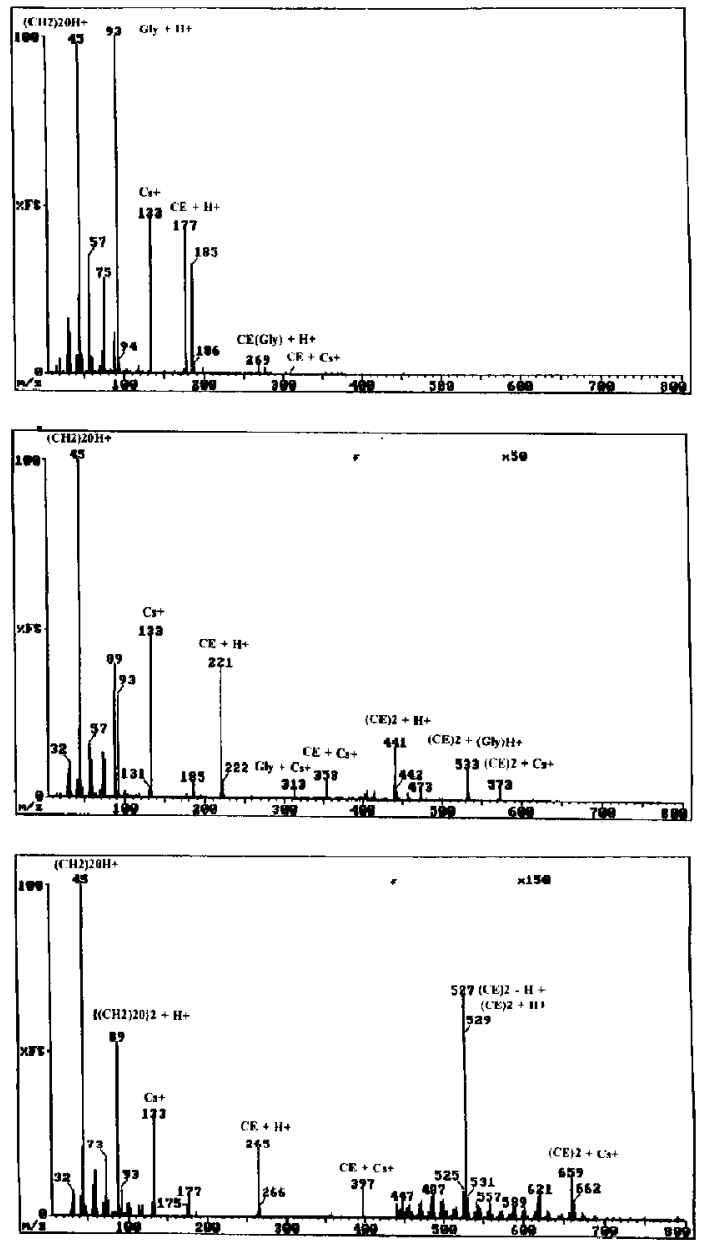

Figure 3, Spectra of crown ether solutions (blank) dissolved in $1: 1 \mathrm{v} / \mathrm{v}$ glycerol-water matrix. Solution 1, 12-crown-4, solution 2, 15-crown-5, and solution 3, 18-crown-6. 

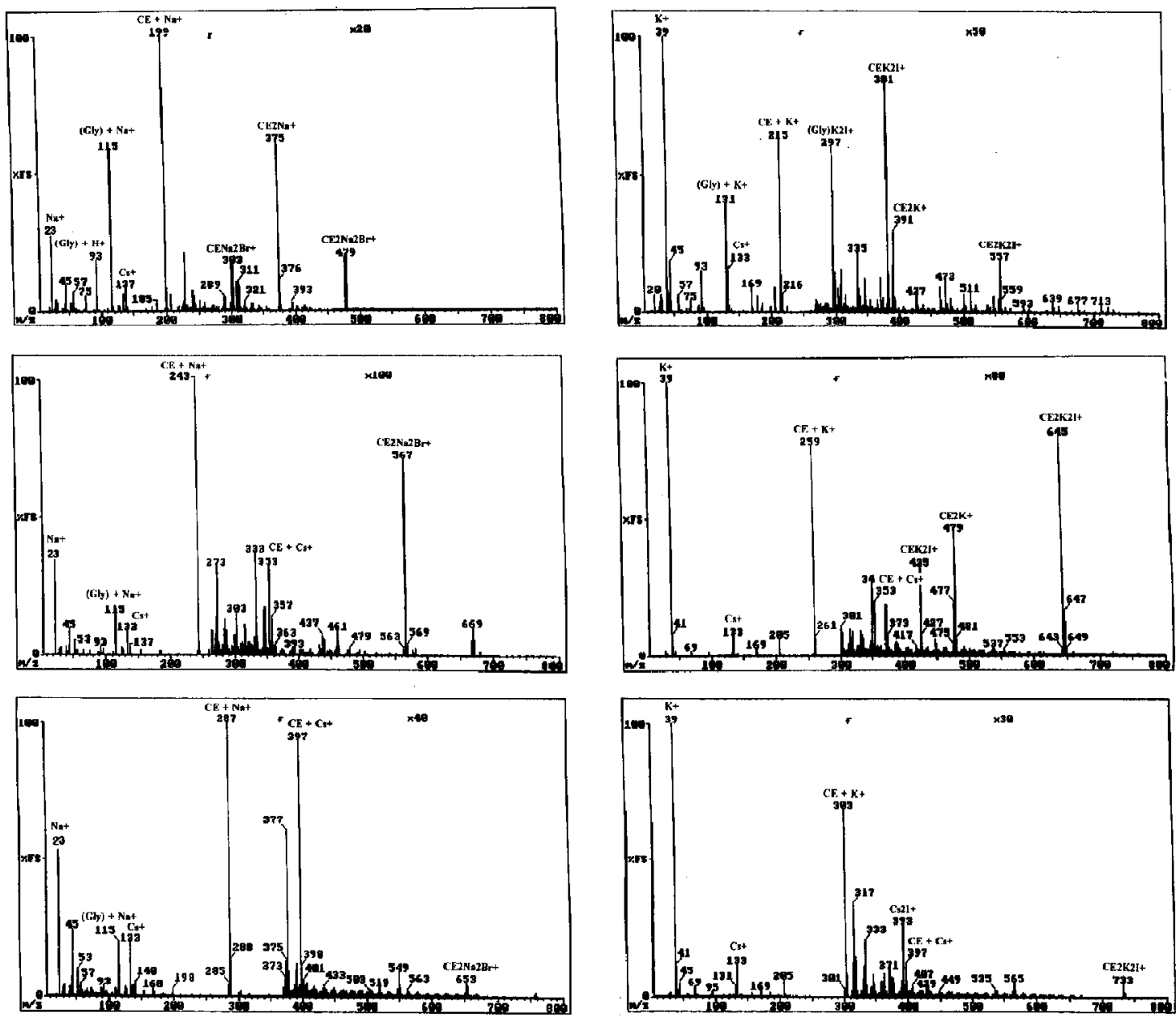

Figure 4. Spectra of $\mathrm{NaBr}(0.25 \mathrm{M})$ and crown ethers $(0.25 \mathrm{M})$ dissolved in 1:1 v/v glycerol-water matrix. Solution 4, 12-crown4, solution 5, 15-crown-5, and solution 6, 18-crown-6.

the selvedge. The evidence is based on data from the following five independent lines of investigation and is discussed in detail in the following sections:

- Blank analysis (solutions of crown ethers in glycerol-water 1:1)

- Comparison of cesiated versus protonated crown ether complexes

- Comparison of cesiated versus sodiated or potassiated crown ether complexes

- Sandwich compound formation

- Cesium iodide cluster formation

Blanks. The spectra of all three of the crown ether blank solutions (Figure 1, solutions 1-3) display a series of peaks that correspond to $[\mathrm{M}+\mathrm{H}]^{+}$and $[\mathrm{M}-$ $\mathrm{H}^{+}$as well as fragment ion peaks from each parent that correspond to ions of $m / z$ at $43,45,87$, and 89 .

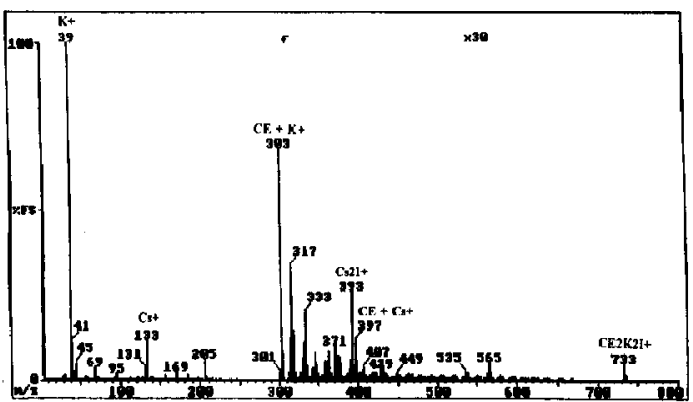

Figure 5. Spectra of $\mathrm{KI}(0.25 \mathrm{M})$ and crown ethers $(0.25 \mathrm{M})$ dissolved in 1:1 v/v glycerol-water matrix. Solution 7, 12-crown4, solution 8, 15-crown-5, and solution 9, 18-crown-6.

Curcuruto et al. [33] provided evidence that other crown ethers subjected to FAB also display these characteristic ion peaks and that they may originate via a selvedge-phase ion-molecule reaction. Specifically addressing this issue, a more recent work by Paul et al. [34] indicated that although $[\mathrm{M}-\mathrm{H}]^{+}$ions were observed in the FAB spectrum for cyclic acetals, a gasphase hydride abstraction reaction would be improbable for the cyclic acetals.

The absence of the crown ether fragment ions in the presence of alkali metals may be because of a stabilizing effect of the metal within the crown ether cavity. If cationization of the crown ethers did occur in the selvedge, the uncomplexed ethers could be present long enough to undergo the apparent selvedge-phase unimolecular decompositions that are characteristic of their presence. It is also possible, however, that the absence of the fragment crown ether peaks could sim- 
ply be the result of the "cleanup" phenomenon of the spectrum observed when alkali halide salts are added to solution [14].

Protonated vs. Cesiated Crown Ethers Complexes. From Figure 3 , it is observed that the $[\mathrm{CE}+\mathrm{Cs}]^{+}$ion abundance is always lower than that of the $[\mathrm{CE}+\mathrm{H}]^{+}$ion. In these unique solutions, an alkali cation is present without a counter halide ion. Ion suppression from neutralization with the halide ion is therefore not an issue. Thermodynamic stability trends from the MeCN data (see Table 1) appear similar to the trends in other solvents and indicate that the protonated crown ether complex has a higher stability constant than a cesiated crown ether complex or any other of the alkali metal crown ether complexes. Although the concentration of the protonated crown ether should be very low in solution (due to the near neutral $\mathrm{pH}$ ), the occurrence of the more abundant $[\mathrm{CE}+\mathrm{H}]^{+}$versus the $[\mathrm{CE}+\mathrm{Cs}]^{+}$ ion may be the result of the direct desorption of the limited quantity of the protonated crown ether that is present in solution. It can be argued, however, that if selvedge-phase ionization occurred, the ion intensity would be the result of a significant acid (or highly acidic gaseous solvent, e.g., $\mathrm{H}_{3} \mathrm{O}^{+}, \mathrm{GlyH}+$ ) concentration within the selvedge. This selvedge acid would have a concentration comparable to that of the $\mathrm{Cs}_{(\mathrm{g})}^{+}$ cation and would be a better competitor for the gaseous-free crown ether than the $\mathrm{Cs}_{(\mathrm{g})}^{+}$cation. If this were in fact the case, then the absence of the protonated crown ether peak for solutions containing the alkali cations would again support the occurrence of direct desorption of $[\mathrm{CE}+\mathrm{M}]^{+}$ion complexes. This is so because if the selvedge acid does compete effectively with a selvedge alkali cation for the crown ether, the protonated crown ether peak would predominate in solutions that contain alkali metal cations. In fact, the protonated crown ether peak intensity is insignificant when alkali metal ions are present in solution (Figures 4 and 5 ).

Comparison of $[C E+C s]^{+}$with $[C E+M]^{+}$. The $[\mathrm{CE}$ $+\mathrm{Cs}]^{+}$ion intensity is always much lower than that of the $[\mathrm{CE}+\mathrm{M}]^{+}$ion intensity. This is true even though thermodynamic data suggest comparable vapor-phase stability constants for all three cations with their respective crown ethers. From Table 2, the stability of 18-crown- $6 \mathrm{Cs}^{+}$is greater in solution than the stability of 18 -crown- $6-\mathrm{Na}^{+}$, yet the ion intensity of the cesium complex is relatively much lower than that of the sodium complex.

Sandwich Compounds. In our experiment we detected two fairly weak ion signals for $\mathrm{Cs}^{+}$sandwich compounds for the analysis of the 18-crown-6-blank and 15-crown-5-blank solutions. A sandwich compound is composed of two crown ethers that coordinate on either side of a cation. In general, sandwich formation occurs only when the cation is larger than the ligand cavity [24]. Sandwich compounds found for the other alkali metals were also detected and include (15crown-5) ${ }_{2} \mathrm{~K}^{+}$, (12-crown-4) $\mathrm{K}^{+}$, and (12-crown-4) ${ }_{2} \mathrm{Na}^{+}$. Ion clusters that imply the inclusion of sandwich compounds also include (15-crown-5) ${ }_{2} \mathrm{~K}_{2} \mathrm{I}^{+}$, (15-crown5) ${ }_{2} \mathrm{Na}_{2} \mathrm{BrI}^{+}$, (12-crown-4) ${ }_{2} \mathrm{Na}_{2} \mathrm{Br}^{+}$, and (12-crown4) ${ }_{2} \mathrm{~K}_{2} \mathrm{I}^{+}$.

In two separate experiments, Zhang et al. [24, 25] demonstrated the formation of sandwich compounds in the gas phase. Recent work by Katritzky et al. [26] reported appearance energies (AE) for the gaseous 15-crown-5- $\mathrm{Cs}^{+}$sandwich to be $33 \mathrm{kcal} / \mathrm{mol}(350 \mathrm{~K})$ $( \pm 8 \mathrm{kcal} / \mathrm{mol})$. In the same work, the $\mathrm{AE}$ of the gaseous 18 -crown-6- $\mathrm{Cs}^{+}$nonsandwich compound is reported at $32 \mathrm{kcal} / \mathrm{mol}(350 \mathrm{~K})( \pm 8 \mathrm{kcal} / \mathrm{mol}) . \mathrm{Al}-$ though there is a fair degree of uncertainty in these measurements, the binding energies of sandwich compounds appear to be comparable to the binding energies of singly complexed compounds in the gas phase. Finally, Zhang et al. [25] reported that rate constants for the reaction

$$
[\mathrm{CE}+\mathrm{M}]^{+}+\mathrm{CE} \rightarrow \mathrm{CE}_{2} \mathrm{M}^{+}
$$

whereby $\mathrm{CE}$ is 15 -crown-5, follow the order $\mathrm{K}^{+}>\mathrm{Cs}^{+}$ $>\mathrm{Na}^{+}$and that the rate constant of the $\mathrm{Cs}^{+}$sandwich is approximately two times higher than that for the formation of the $\mathrm{Na}^{+}$sandwich in the gase phase. The free energy values (kilocalories per mole) for 1:2 sandwich complexation in $\mathrm{MeOH}$ are comparable to reported values [35] of $\mathrm{K}^{+}(3.38-4.04), \mathrm{Na}^{+}$(3.78), and $\mathrm{Cs}^{+}$(3.45).

Thus, our observation that the ratio $\mathrm{CE}_{2} \mathrm{M}^{+}-[\mathrm{CE}+$ $\mathrm{M}^{+}$for the 15 -crown-5- $\mathrm{Cs}^{+}$complex is approximately one half the ratio of $\mathrm{CE}_{2} \mathrm{M}^{+}-\mathrm{CEM}{ }^{+}$for the 15 -crown-5- $\mathrm{Na}^{+}$complex (including sandwich adducts) runs contradictory to recent gas-phase data. The likely reason for the discrepancy may be the result of contributions to the 15 -crown-5- $\mathrm{Na}^{+}$sandwich complexes from direct desorption.

Cesitum Iodide Clusters. The $\mathrm{Cs}_{2} \mathrm{I}^{+}$ion peak at $\mathrm{m} / \mathrm{z}$ 393 (Figure 2, solution 9) is more intense than the 18-crown- $6-\mathrm{Cs}^{+}$ion peak at $m / z$ 397. This indicates that there is a greater likelihood for $\mathrm{Cs}_{(\mathrm{g})}^{+}$to combine with $\mathrm{I}_{(\mathrm{g})}^{-}$and then combine with another $\mathrm{Cs}_{(\mathrm{g})}^{+}$than it is for $C s_{(g)}^{-}$to react with one free $18-$ crown- $\sigma_{(g)}$. The "freeing up" of anions to enhance reactivity via complexation with cations is a common use of crown ethers in solutions, and this phenomenon appears to be occurring in the gas phase as well. In solution, complexation follows the solvation of the salt. Unlike in the condensed phase, however, the gas phase that is evident in the selvedge provides no solvation and the dissolution of a salt is highly endothermic. For this reason, the "freeing up" phenomenon should not be prevalent in the gas phase. The spectra can thus be rationalized if we consider that the $\mathrm{K}^{+}$ion enters the gas phase in the complexed state. In this manner, the 
anions would be "freed up" and the observed spectrum could be explained.

The $\mathrm{Cs}_{2} \mathrm{I}^{+}$ion peak does not appear in the two spectra of solutions containing $15-$ crown $-5-\mathrm{K}^{+}$or $12-$ crown $-4-K^{+}$. As mentioned before, ion signal intensity suppressions may be the result of the "spectrum cleanup" that results from the addition of salts. The same concentration of preformed ions, however, is present in all solutions containing the potassium iodide solution. The absence of the $\mathrm{Cs}_{2} \mathrm{I}^{+}$ion peak may be rationalized from the knowledge that a majority of the potassium cations are complexed with the 18crown-6 (at 96\%). However, the potassium cation is complexed to a much lesser extent with 15-crown-5, and to an even lesser extent with 12-crown-4. Thus, if direct desorption occurred, uncomplexed sputtered $\mathrm{K}_{(\mathrm{g})}^{+}$ would be much more readily available from solutions that contain the smaller crown ether complexes. This would permit the rapid neutralization reaction to occur between $\mathrm{K}_{(\mathrm{g})}^{+}$and $\mathbf{I}_{(\mathrm{g})}^{-}$, and would concomitantly reduce the availability of $\mathrm{I}_{(\mathrm{g})}^{-}$to react with $\mathrm{Cs}_{(\mathrm{g}) \text {, }}^{+}$, thus explaining the reduction in the $\mathrm{Cs}_{2} \mathrm{I}^{+}$ion signal.

An argument can be made for the possibility that a rapid selvedge-phase reaction of the $\mathrm{K}_{(\mathrm{g})}^{+}$with free 18 -crown-6 $6_{(\mathrm{g})}$ is responsible for "tying up" the $\mathrm{K}_{(\mathrm{g})}^{+}$, thus permitting the $\mathrm{Cs}_{(\mathrm{g})}^{+}$reaction with $\mathrm{I}_{(\mathrm{g})}^{-}$. Experimental conditions have been set, however, such that the concentrations of the potential reactants $\left(\mathrm{K}_{(\mathrm{g})}^{+}, \mathrm{I}_{(\mathrm{g})}^{-}\right.$, and 18 -crown- $\left.6_{(g)}\right)$ are identical in solution (and presumably the selvedge). Because the reaction of uncomplexed $\mathrm{K}_{(\mathrm{g})}^{+}$with $\mathrm{I}_{(\mathrm{g})}^{-}$is far more energetically and /or sterically favorable than either the reaction of $\mathrm{K}_{(\mathrm{g})}^{+}$with 18-crown- $6_{(g)}$ or the reaction of $\mathrm{Cs}_{(g)}^{+}$with $I_{(g)}^{-}$, this appears unlikely. Therefore, only if the $\mathbf{K}_{(g)}^{+}$is complexed at all times can the spectrum be justified.

\section{Summary of Experimental Results}

The data indicate that a direct desorption mechanism of crown ether complexes is responsible for the measured ion signal from condensed phase mixtures. The five lines of investigation and the subsequent findings are summarized below:

- Blank analysis indicates the stabilizing effect of metal cations in the gas phase.

- Comparison of the spectra of cesiated versus protonated crown ether complexes indicates that direct desorption of protonated crown ether complexes occurs. If a gas-phase competition between $\mathrm{Cs}_{(\mathrm{g})}^{+}$and $\mathrm{H}_{(\mathrm{g})}^{+}$(or any gaseous acid) occurred, then a predominance of $[\mathrm{CE}+\mathrm{H}]^{+}$over $\left[\mathrm{CE}+\mathrm{M}^{+}\right.$would also be expected. The spectra demonstrate, however, a predominance of $[\mathrm{CE}+\mathrm{M}]^{+}$over $[\mathrm{CE}+\mathrm{H}]^{+}$, where $\mathrm{M}^{+}$is either $\mathrm{Na}^{+}$or $\mathrm{K}^{+}$.

- Comparison of the spectra of cesiated versus sodiated or potassiated crown ether complexes demonstrates the predominance of direct desorption $\left(\mathrm{Na}^{+}\right.$ and $\mathrm{K}^{+}$complexes) versus the competing gas-phase $\left(\mathrm{Cs}^{+}\right.$complexes) process.

- Analysis of the spectra of sandwich compounds supports a direct desorption process and is contradictory to recent gas-phase complexation data.

- Analysis of the cesium iodide clusters demonstrates the condensed-phase phenomenon of "freeing up" anions. The spectra also indicate that cations are complexed with crown ethers at all times after direct desorption.

\section{Conclusion}

On the basis of the experimental data obtained for the crown ethers and alkali metal cations, it appears that although gas-phase processes for FAB cationization of crown ethers do occur to some extent, a majority of the ion signal arises from preformed condensed-phase cationization. The data presented demonstrate that a strongly complexed solvated noncovalent compound may survive the fast-ion impact intact. This in turn provides the possibility that FAB and LSIMS may be utilized in probing condensed-phase noncovalent interactions. The aim of future work will be to assess the generality of this phenomenon to other noncovalent compounds and to investigate the correlation of the ion spectra with condensed-phase equilibria of crown ether-metal ion complexes.

\section{References}

1. Lyon, P. A., Ed. Desorption Mass Spectrometry: Are SIMS and $F A B$ the Same?; American Chemical Society, Washington, DC, 1985.

2. Benninghoven, A.; Evans, C. A.; McKeegan, K. D.; Storms, H. A.; Werner, H. W., Eds. Secondary Ion Mass Spectrometry; SIMS VII; John Wiley \& Sons, Chichester, 1990.

3. Williams, D. H.; Bradley, C.; Bojesen, G.; Santikarn, S.; Taylor, L. C. E. I. Am. Chem. Soc. 1981, 103, 5700-5704.

4. Caprioli, R. M., Ed. Continuous-Flow Fast Atom Bombardment Mass Spectrometry; John Wiley \& Sons: Chichester, 1990.

5. Roepstorff, P.; Hojrup, P.; Moller, J. Biomed. Mass Spectrom. 1985, 12, 181-189.

6. Meijers, J. C. M.; Lim, C. K.; Lawson, A. M.; Peters, T. J. J. Chromatogr. 1986, 352, 231-239.

7. Brown, S. J.; Miller, J. M. J. Chem. Soc, Perkin Trans. 2 1987, 1129-1132.

8. Pachuta, S. J.; Cooks, R. G. In Desorption Mass Spectrometry: Are SIMS and FAB the Same?; Lyon, P. A. Ed.; American Chemical Society: Washington, D. C., 1985; $\mathrm{p} 1$.

9. Williams, P. In Secondary Ion Mass Spectrometry; SIMS VII; John Wiley \& Sons, Chichester, 1990; p 15.

10. Todd, P. J. In Secondary Ion Mass Spectrometry; SIMS VII; John Wiley \& Sons, Chichester, 1990; p 25.

11. Ganem, B.; Li, Y.; Henion, J. D. J. Am. Chem. Soc. 1991, 113, 6294-6296

12. Ganem, B.; Li, Y.; Henion, J. D. J. Am. Chem. Soc. 1991, 113, $7818-7819$.

13. Caprioli, R. M, Anal. Chemt. 1983, 55, 2387.

14. Sunner, J. A.; Kulatunga, R.; Kebarle, P. Anal. Chem. 1986, 58, 2009-2014. 
15. Sunner, J.; Morales, A.; Kebarle, P. Anal. Chem. 1987, 59. $1378-1383$.

16. Sunner, J. A.; Kulatunga, R.; Kebarle, P. Anal. Chem. 1986, 59. $1312-1316$.

17. Schroder, E.; Munster, H.; Budzikiewicz, H. Org. Mass Spectrom. 1986, 21, 707-715.

18. Michaud, D. P.; Brennan, T. F.; Vouros, P. Presented at 36th Annual Meeting of the American Society for Mass Spectrometry, San Francisco, CA, 1988; p 161.

19. Miller, J. M.; Balasanmugam, K.; Fulcher, A. Org. Mass Spectromt. 1989, 24, 497-503.

20. Balasanmugam, K.; Hartman, J. S.; Miller, J. M.; Yuan, Z. Can. J. Chem. 1989, 67, 685-688.

21. Michaud, D. P.; Kyranos, J. N.; Brennan, T, F.; Vouros, P. Anal. Chem. 1990, 62, 1069-1074.

22. Johnstone, R. A. W.; Rose, M. E. J. Chem. Soc. Chem Commun. 1983, $1268-1270$.

23. Bonas, G.; Bosso, C.; Vignon, M. R. Rapid Commun. Mass Spectrom. 1988, 2, 88-89.

24. Zhang, II.; Chu, I.; Lening, S.; Dearden, D. V. J. Am. Chen. Soc. 1991, 113, 7415-7417.

25. Zhang, H.; Dearden, D. V. J. Am. Chem. Soc. 1992, 714, 2754-2755.

26. Katritzky, A. R.; Malhotra, N.; Ramanathan, R.; Kemerait, R. C.; Zimmerman, J. A., Jr.; Eyler, J. R. Rapid Commun. Mass Spectrom. 1992, 6, 25-27.
27. Dugas, H. In Bioorganic Chemistry; $\Lambda$ Chemical Approach to Enzyme Action; Springer-Verlag: New York, 1989; Chap. 5.

28. Weber, E.; Toner, J. L.; Goldberg, I.; Vogtle, F.; Laidler, D. A.; Stoddart, J. F; Bartsch, R. A.; Liotta, C. L. Crown Ethers and Analogs; John Wiley \& Sons Ltd: Chichester, 1989.

29. Inoue, Y.; Gokel, G. W., Eds. Cation Binding by Macracycles, Complexation of Cationic Species by Crown Ethers; Marcel Dekker: New York, 1990.

30. Pachuta, S. J.; Cooks, R. G. In Desorption Mass Spectrometry: Are SIMS and FAB the Same?; Lyon, P. A., Ed.; American Chemical Society, Washington, DC, 1985. Chap. 1.

31. Markey, S. P.; Shih, M. In Continuous-Flow Fast Atom Bombardment Mass Spectrometry; Caprioli, R. M., Ed.; John Wiley \& Sons: Chichester, 1990, Chap. 3.

32. Colton, R. J.; Kidwell, D. A.; Ramseyer, G. O.; Ross, M. M. In Desorption Mass Spectrontetry: Are SIMS and FAB the Same?; Lyon, P. A., Ed.; American Chemical Society: Washington, DC, 1985; Chap. 10.

33. Curcuruto, O.; Traldi, P.; Moneti, G.; Corda, I..; Podda, G. Org. Mass Spectrom. 1989, 26, 713-717.

34. Paul, G. J. C.; Bourg, S.; Bertrand, M. J. Rapid Commun. Mass Spectrom. 1992, 6, 85-88.

35. Inoue, Y.; Hakushi, T. In Cation Binding by Macrocycles, Complexation of Cationic Species by Crown Ethers; Marcel Dekker: New York, 1990; Chap. 1, p. 39. 